\section{Reply to Painful Digital Fissures}

\section{To the Editor:}

The authors would like to thank Dr Baird for her comments and agree that fissuring of the fingers does indeed occur across a wide range of different climates. However, our collective experience at both sea level and high altitude leads us to believe that the frequency is greater, and extent of these injuries considerably worse, in the cold, dry environment common to the altitudes found in the greater ranges.

Like Dr Baird, we also believe that the presence of type II diabetes mellitus is not a prerequisite for fissure formation. Nonetheless, we feel that the interplay between the disease and the aforementioned environmental factors experienced at high altitude provides exceptional opportunity for skin fissure formation. We therefore feel this subject is deserving of further discussion and, ideally, systematic investigation.

Jeremy S. Windsor, MB ChB

Paul Richards, MB ChB

London, UK

George Rodway, $\mathrm{PhD}$, CNP

Columbus, OH, USA

\section{A Case of an Alpinist with a Patent Foramen Ovale and High-Altitude Pulmonary Edema at Moderate Altitude}

To the Editor:

A 60-year-old man started coughing and feeling weak after a night at $3100 \mathrm{~m}$ altitude in the Alps, and after continuing ascent, deteriorated quickly to breathlessness during rest, crackling noises whilst breathing, and blue lips and fingernails. His mountain partners suspected high-altitude pulmonary edema (HAPE) and brought him down to the valley immediately, where he recovered within a short time without medical help. The alpinist is an experienced climber who had undertaken numerous

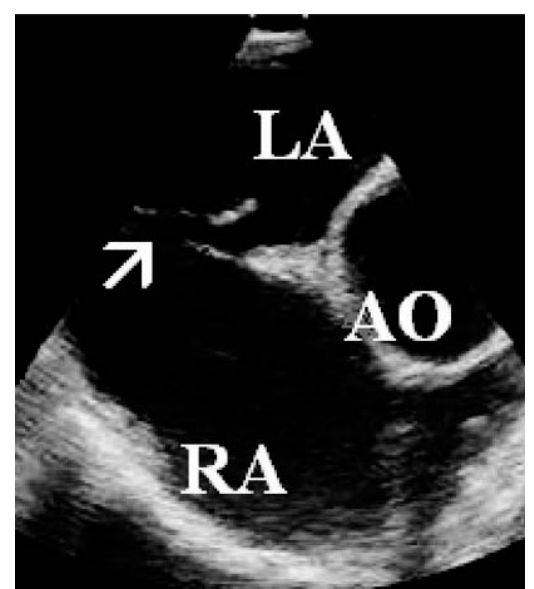

Figure. Patent foramen ovale (arrow). LA indicates left atrium; RA, right atrium; and AO, aorta (transesophageal echocardiography).

mountain tours below $3000 \mathrm{~m}$ altitude in the Alps without any medical problems. Because of a heart murmur, transesophageal echocardiography had been performed a few years prior and revealed a patent foramen ovale; no consequences to this finding had been suggested at that time (Figure). Patent foramen ovale is 4 times more frequent in HAPE-susceptible than in HAPE-resistant mountaineers. A large patent foramen ovale contributes to exaggerated arterial hypoxemia and facilitates HAPE. ${ }^{1}$

Georg Röggla, MD

Daniela Mandelburger, MD

Neunkirchen, Austria

Bernadetta Moser, MD

Bozen, Italy

Thomas Binder, MD

Vienna, Austria

\section{Reference}

1. Allemann Y, Hutter D, Lipp E, Sartori C, Duplain H, Egli M, Cook S, Scherrer U, Seiler C. Patent foramen ovale and high-altitude pulmonary edema. JAMA. 2006;296:29542958. 